\title{
Country-of-Origin vs. Foreign Branding: Does Incongruent Verbal Package Information Affect Consumers' Purchase Intention?
}

\author{
Ana Marija Morovican \\ University of Applied Sciences Burgenland, Austria \\ Claudia Kummer \\ University of Applied Sciences Burgenland, Austria
}

\begin{abstract}
This contribution investigates under which conditions consumers can identify a product's country of origin when confronted with conflicting information on the product package. Our study draws on current literature on the country-of-origin effect and on foreign branding, a naming strategy designed to evoke associations of a favoured origin by means of the language or spelling cues included in the brand name. The study we conducted has two major objectives. The first one is to ascertain how much attention is paid to the country-of-origin at the point of sale. The second one is to clarify whether foreign branding effects can also be found in connection with the Croatian language. Therefore, an eye-tracking experiment with a follow-up questionnaire was conducted using a student sample. Results showed that attention can be distracted from the country of origin by positioning this element on the back label. Interestingly, findings also indicated that label design, price and shelf positioning influence the buying decision more than congruency of country of origin and brand name. It can further be concluded that incongruence between the country of origin and the language of the brand name seems to be less important for German and English branded olive oils. However, the results for Croatian branded olive oils were clearly better in a condition when those elements were congruent.
\end{abstract}

Keywords: strategic brand management, foreign branding, country-of-origin effect, eye tracking technology, product package, consumer behaviour

JEL classification: M310

\section{Introduction}

Throughout their purchase decision process at the point of sale (POS), consumers are confronted with different kinds of information featured on the product package. Among others, they can find the country-of-origin (COO) of the product. The influence of this information on product evaluation is known as the country-of-origin effect (COE) (Tran et al., 2013). Another typical information element of the product package is the brand name. If the language used for the brand name is not identical with the national language of the COO, a foreign branding strategy is followed (Leclerc et al., 1994). However, taking into consideration the fact that this strategy leads to conflicting information on the product package the question arises to what extent consumers are capable of identifying the true country of origin. Therefore the objectives of this paper are to ascertain how much attention consumers pay to the COO information during product evaluation at the POS or 
respectively to clarify whether consumers refer to the language of the brand name to identify the COO.

\section{Literature review}

The country-of-origin effect (COE). The COE occurs when the COO of one product is evaluated as superior than the $\mathrm{COO}$ of another product. For this judgement, consumers use national stereotypes (Po-Young et al., 2010). National stereotypes are used, as consumers assess the COO according to two dimensions: (1) perceived competency and (2) perceived warmth. Therefore, different COEs are reported between product categories of the same country (Kramer et al., 2008). Due to ethnocentric tendencies, consumers tend to be sceptical regarding products with a foreign origin; in those cases the COE predominates only if there is no national product among the choice of products (Chryssochoidis et al., 2007).

Foreign branding strategy. The basic assumption underlying the foreign branding strategy is that consumers use the language of a brand name as a cue to infer the product's COO (Klein et al., 2012). This notion is supported by the evidence that the $\mathrm{COE}$ is linked closely to the perceived COO, rather than the actual COO (Magnusson et al., 201 1). Leclerc et al. (1994) reported higher consumer ratings in brand name favourability and perception of hedonic products, in this case perfume, for a French brand name as compared to an English brand name. A favourable perception of a language might vary across countries and product categories; so far, English brand names have proven to be a safe choice for global brands (Soto et al., 2009). However, the foreign branding strategy is prone to upset consumers if the incongruence between brand name language and the true COO's native language is revealed. Upon detection of incongruence, Melnyk et al. (2013) found a decrease in purchase intention particularly for hedonic products, albeit the negative influence of incongruence seemed less strong for utilitarian products.

Slavic language perception. In this research, we will examine whether congruence of the language used for the brand name and the COO have effects on the purchase decision at the POS. Studies on foreign branding typically focus on the English and the French language. It needs to be clarified if foreign branding effects can also be found in connection with other languages (Soto et al., 2009). Since Slavic languages have not yet been investigated in foreign branding research, the experiment aims to explore foreign branding in the Croatian language setting.

In the following, we first present our Research Questions and formulate hypotheses. Then we illustrate research design and procedures. Last, we present and discuss the results as well as the limitations of the study before we finally come to the conclusion.

\section{Research questions and hypotheses}

It is still unclear to which extent COO information is actively sought at the POS (Magnusson et al., 2011). The real-life buying situation is influenced by a large quantity of environmental factors which may distract consumers' attention and make it more difficult for them to get accurate COO information. Since existing studies have operated in laboratory conditions, there is a need to investigate a field situation for supposable differences in behaviour (Melnyk et al., 2013). Although the COE has been investigated in-depth, a number of questions have not been addressed so far. Therefore, the study we conducted aims to answer the following Research Questions: 
- (RQ1): Which information element of the product package attracts more attention at the POS: brand name or country of origin?

- (RQ2): Which of those two elements is preferably used for the interpretation of the country of origin at the POS?

- (RQ3): In what ways are information search and buying decision influenced by congruence vs. incongruence of brand name and country of origin?

In this paper the first two Research Questions will only be discussed briefly. The focus is laid on Research Question 3. Therefore we introduce hypotheses only for Research Question 3 in the paragraph below, addressing the potential influence of "incongruence awareness" as follows:

- $\mathrm{H3a}$ ): At the POS, purchase intention is lower when brand name and COO are incongruent than when these elements are congruent;

- H3b): Visual attention for the COO and for the brand name is higher when brand name and $\mathrm{COO}$ are incongruent than when these elements are congruent;

\section{Methodology}

An eye-tracking experiment with a follow-up questionnaire was conducted, relying on a student sample to simulate a buying situation. The eye-tracking approach allows tracking pre-attentive behaviour (Helfman et al., 2011) which is undistorted by social desirability bias, lack of verbalisation skills or rationalization tendencies (Karmasin et al., 2011). Two types of eye movements were recorded and analysed: While saccades are very short eye movements, fixations last longer. Fixations are important for scene perceptions and therefore good indicators of visual attention (Chandon et al., 2009).

The product selected for the study was olive oil. Besides Croatia, three further countries of origin were chosen based on their COO impact: 1) California, as a part of the USA, was expected to have a very positive COO image. 2) Austria was expected to be of interest for participants with ethnocentric tendencies, while 3) Romania, being part of Eastern Europe, was considered to have a negative COO image. According to the information found on the website of the International Olive Council, California and Croatia are actually olive oil producers, whereas neither Austria nor Romania produce olive oil themselves. For consumers who are aware of this fact, a Croatian or Californian brand name would likely evoke feelings of congruency, whereas German or Romanian brand names would probably cause confusion, incongruence, or at least make consumers wonder about the true COO.

\section{Pre-Study}

Fictitious brand names were generated so as to exclude brand popularity as a confounding factor. For this list of brand names, a manipulation check was conducted. The pronunciation of the brand name was meant to sound like typical Croatian, English or German words. In an online survey, 69 participants were asked to match each brand name with one of those languages; then, we asked them to choose their favourite brand name of each language group. The brand names "Olivey" and "Olivić" counted the largest number of votes for the English and Croatian brand name. Among the German brand names, the majority considered "Olichen" to be appropriate, although language associations were less intense than for the other brands. Therefore, the brand name was changed to "Ölichen" to increase the language association by using the character "ö", which is typical for the German linguistic area. 


\section{Data collection}

Students from the University of Applied Sciences Burgenland, Austria, were asked to participate in the experiment. The sample consisted of $53 \%$ female and $47 \%$ male respondents of which almost $90 \%$ were between 18 and 34 years old. $70 \%$ of the students were enrolled in an extra-occupational study programme; this explains why $65 \%$ of the students stated to be the head of their own household. The big majority (80 \%) of the students claimed to use olive oil at least once a week.

The experiment was carried out in the "Productive Work Laboratory" at the university campus, comprising a half-open recreational area of $40 \mathrm{~m} 2$ which is equipped with moveable furniture, adaptable lighting conditions, and background music. These features generate a lot of student traffic, allow for experimental control of variables, and create an appropriate atmosphere to simulate a grocery shopping condition.

Table 1

Experimental Groups

\begin{tabular}{|l|l|l|l|}
\hline Group & Product 1 & Product 2 & Product 3 \\
\hline $\mathbf{1}$ & Olivić from Croatia (c) & Ölichen from Austria (c) & Olivey from Romania (ic) \\
\hline $\mathbf{2}$ & Olivić from Romania (ic) & Ölichen from Austria (c) & Olivey from California (c) \\
\hline $\mathbf{3}$ & Olivić from Croatia (c) & Ölichen from Romania (ic) & Olivey from Romania (ic) \\
\hline \hline $\mathbf{4}$ & Olivić from Romania (ic) & Ölichen from Romania (ic) & Olivey from California (c) \\
\hline
\end{tabular}

Note: (c) expresses a congruent condition while (ic) expresses an incongruent condition.

Source: Authors' own findings

115 students were randomly assigned to one of four experimental groups (cp. table 1), each containing three products which were mainly characterised by varying brand names and the position and congruency of the COO information cue. Those groups were further divided into three subgroups, each to control for interfering variables such as pricing, shelf position and label design. For example, Ölichen from Austria was once presented at the first position, with the highest price and a fancy label design, next it was presented at the second position, with the lowest price and a more traditional label design, and finally it was presented at the third position, with a medium price and a creative-arts label design. Finally, the participants were randomly assigned to one of twelve groups.

Secondly, participants were requested to put on mobile eye tracking glasses (ETG $30 \mathrm{~Hz}$ by SMI Vision) and were handed a shopping basket. We asked them to imagine a shopping situation in which they wanted to buy olive oil. For this, they were led in front of a shelf displaying the three different olive oil bottles, and were given one minute's time to take a buying decision, l.e. to put their favoured product into the basked. During the evaluation process, while participants examined the labels and reached for bottles to see their back labels, their eye movements were recorded by the eye tracking glasses. After the buying decision was accomplished, respondents were asked to fill out the questionnaire. Its purpose was, above all, to ascertain whether the students were able to recall the brand name and the COO of the olive oil product they had chosen.

\section{Analysis}

All in all, eye-tracking data from 99 participants who completed a follow-up questionnaire qualified for the analysis. Three products were presented to each participant during the experiment, in total 297 facings in sum. In order to test the hypotheses dealing with visual attention, we defined areas of interest (brand name, 
and COO information cue) and analysed three parameters most commonly used to infer visual attention (Holmqvist et al., 2011): Hit ratio reports the percentage of participants who perceived the area of interest; dwell time denominates the average length of all fixations spent by a participant in the area of interest and is expressed in milliseconds (ms); and number of revisits indicates how many times the viewer directed their gaze back to the point of interest once they had left it.

\section{Results}

In the findings below, the first two paragraphs deal briefly with results for Research Question 1 and 2. Then, the results for Research Question 3 are presented in more detail.

\section{RQ1 - Perception of brand name and COO at the POS}

Dwell time for the brand name in sum is $119,866 \mathrm{~ms}$. This number divided by 194 cases in which the brand name was focused leads to an average dwell time of $618 \mathrm{~ms}$. The average dwell time for the COO information is $132,767 \mathrm{~ms}$ and as the coO information was focused 177 times the average dwell time is $750 \mathrm{~ms}$ and thus higher. The hit ratio for the brand name is $65.3 \%$ and the hit ratio for the COO information cue is $59.6 \%$. There is a remarkable difference for the hit ratio depending on the position of the COO information cue. $73.7 \%$ of the participants looked at the $\mathrm{COO}$ information when it was placed on the front label of the product while only $39.7 \%$ of the participants looked at this information when placed on the back label. Furthermore, the brand name was revisited 210 times in sum, while the COO information was revisited 195 times.

\section{RQ2 - Interpretation of the COO}

When the COO was positioned at the front label for $82.8 \%$ of the participants an accurate COO recall was possible while it was only possible for $49 \%$ of the participants to name the correct $\mathrm{COO}$ when the information was placed on the back label. There were barely cases where a connection between a wrong recall of the $\mathrm{COO}$ and the language used for the brand name could be observed.

\section{RQ3 - Perception of incongruence}

Looking at purchase intentions at first sight, there are hardly any differences between the congruent and the incongruent labels. In $58.6 \%$ of the cases, participants chose an olive oil with congruent brand name and COO. Thus, in $41.4 \%$ of the buying simulations, participants bought olive oil with a foreign branding strategy. However, table 2 below gives a deeper insight to those findings. Firstly, one can see that the combination of design, positioning and price for experimental subgroup "Dl" was the least accepted selection while "D3" was most frequently chosen. Secondly, and more interestingly, the table shows that for olive oil with a Croatian brand name, the differences in the actual buying decisions between made in Croatia (congruent setting) and made in Romania (incongruent setting) were more decisive than for the other language-country combinations. The brand "Olivić" made in Romania was presented 49 times to the participants, leading to a purchase in $27 \%$ of the cases. "Olivić" made in Croatia was presented 50 times and was chosen in $50 \%$ of the cases. Furthermore, it must be noted that "Ölichen" was chosen slightly more often with Romania as the COO (cp. table 2). 
Table 2

Buying Decisions

\begin{tabular}{|c|c|c|c|c|c|c|c|c|c|}
\hline & $\begin{array}{l}\text { D1 } \\
\text { chosen }\end{array}$ & $\begin{array}{l}\text { D1 in } \\
\%\end{array}$ & $\begin{array}{l}\text { D2 } \\
\text { chosen }\end{array}$ & $\begin{array}{l}\text { D2 in } \\
\%\end{array}$ & $\begin{array}{l}\text { D3 } \\
\text { chosen }\end{array}$ & $\begin{array}{l}\text { D3 in } \\
\%\end{array}$ & Sum & Facings & $\begin{array}{l}\text { in } \% \text { of } \\
\text { facings }\end{array}$ \\
\hline Ölichen Romania & 2 & $20 \%$ & 1 & $10 \%$ & 7 & $70 \%$ & 10 & 42 & $24 \%$ \\
\hline Ölichen Austria & 4 & $17 \%$ & 6 & $26 \%$ & 13 & $57 \%$ & 23 & 56 & $41 \%$ \\
\hline Olivić Romania & 1 & $8 \%$ & 4 & $31 \%$ & 8 & $62 \%$ & 13 & 49 & $27 \%$ \\
\hline Olivić Croatia & 4 & $16 \%$ & 8 & $32 \%$ & 13 & $52 \%$ & 25 & 49 & $51 \%$ \\
\hline Olivey Romania & 1 & $8 \%$ & 3 & $23 \%$ & 9 & $69 \%$ & 13 & 49 & $27 \%$ \\
\hline Olivey California & 1 & $7 \%$ & 2 & $14 \%$ & 11 & $79 \%$ & 14 & 49 & $29 \%$ \\
\hline
\end{tabular}

Note: $\mathrm{D} 1$ = first position, highest price \& fancy label design; $\mathrm{D} 2$ = second position, lowest price, traditional label design; D3 = third position, medium price \& creative-arts label design. $\mathrm{n}=297$ facings. Source: Authors' own findings.

Based on our findings, $\mathrm{H} 3 \mathrm{a}$ cannot be confirmed. For the English brand name, the difference in the actual purchase rate is small whereas for the Croatian brand name, differences call for further observation. A qui-square test was not carried out as the expected values for the buying decisions were below 5 in the majority of the cases. However, H3b can be partly accepted. Although there is only a minimal difference in connection with the hit ratio of the brand name in the congruent $(63 \%)$ and incongruent (68\%) condition, the difference is much higher for the COO information. Here, the hit ratio in congruent condition is $74 \%$ and in incongruent condition $40 \%$. There are hardly any differences in dwell time in average for the brand name while dwell time in average is higher for the COO on the back label (915ms) than on the front label $(661 \mathrm{~ms})$. Furthermore, revisits differ in the various groups. While there were more revisits in average for the brand name in incongruent condition, the opposite was true for the COO.

Table 3

Eye-Tracking Results

\begin{tabular}{|l|r|r|r|l|l|r|}
\cline { 2 - 7 } \multicolumn{1}{c|}{} & $\begin{array}{l}\text { Dwell time } \\
\text { brand name } \\
\text { on average }\end{array}$ & $\begin{array}{l}\text { Dwell time } \\
\text { COO on } \\
\text { average }\end{array}$ & $\begin{array}{l}\text { Average Hit } \\
\text { ratio brand } \\
\text { name }\end{array}$ & $\begin{array}{l}\text { Average } \\
\text { Hit ratio } \\
\text { COO }\end{array}$ & $\begin{array}{l}\text { Average } \\
\text { revisits brand } \\
\text { name }\end{array}$ & $\begin{array}{l}\text { Average } \\
\text { revisits } \\
\text { COO }\end{array}$ \\
\hline $\begin{array}{l}\text { Incongruent } \\
\text { condition }\end{array}$ & $606 \mathrm{~ms}$ & $915 \mathrm{~ms}$ & $68 \%$ & $40 \%$ & 1.2 & 0.9 \\
\hline Congruent condition & $629 \mathrm{~ms}$ & $661 \mathrm{~ms}$ & $63 \%$ & $74 \%$ & 0.9 & 1.2 \\
\hline
\end{tabular}

Source: Authors' own findings.

\section{Discussion}

All in all, we acquired several noteworthy insights with the experiment conducted. It was confirmed that consumers' attention for the COO can be influenced by varying the position on the product package. This was shown on the one hand by the eyetracking data and on the other hand by the COO recall rate. That is to say, more participants perceived and correctly reported the COO when it was placed on the front label, as opposed to when it was placed on the back label. In the cases where participants perceived the incongruent COO information cue on the back label the average dwell time was much higher than in the congruent setting. However, it was shown that composing congruent vs. incongruent bits of information on the labels 
did not affect the purchase rate for English branded olive oils. For "Olivey" the COO had seemingly no effects on the buying decision. On the contrary, for "Olivić" and "Ölichen" the purchase rate for the incongruently labelled product was considerably lower than for its congruent counterpart.

There are three possible explanations for this result. (1) The participants of the sample may not have believed that California had the competency to produce olive oil and/or the country did not evoke comparable emotions as Croatia for this product. Thus, there is a lower COE for olive oil from California than for olive oil from Croatia. (2) Participants may have evaluated a Slavic branded product in more detail than an English branded product. (3) For part of the sample ethnocentric tendencies resulted in a preference for olive oil made in Austria.

It was interesting to observe the fact that design, price and shelf position influenced the buying decision more than logical consistency of the COO. This phenomenon supports the assumption that consumers are easily distracted from the COO information. Still, we got no evidence that consumers refer to the language of the brand name to identify the $\mathrm{COO}$ as there were barely cases where a wrong cOO recall could be connected with the language used for the brand name.

\section{Conclusion}

By using an eye-tracker during a buying simulation and conducting a follow-up questionnaire Research Question 1 and Research Question 3 could be answered. Results showed that in a purchase situation at the POS, the brand name attracts more attention than the $\mathrm{COO}$. When the $\mathrm{COO}$ is prominently placed on the front label there is only a slight difference in average dwell time and hit ratio between COO information and brand name. In those cases where the COO was placed on the back label, the hit ration was much lower. Thus it was revealed that incongruence of brand name and $\mathrm{COO}$ can be obscured by positioning of the COO element on the back label, given that participants paid less attention to the back side. Still, the average dwell time for the COO on the back label was much higher than for the $\mathrm{COO}$ on the front label. This indicates that perceived incongruence leads to more thorough information processing due to the irritation caused by the conflicting package information. For English branded olive oils, this incongruence seemed to be unimportant for the buying decision. For Croatian and German branded olive oil, incongruence affected purchase intention substantially. So "Olivić" made in Croatia was chosen almost two times more often than "Olivić" made in Romania.

Answering Research Question 2, we could not establish any evidence that the brand name was used for COO interpretation. There are two further limitations in the experiment. Firstly, the experiment was conducted with only one product type. In a real-life situation, consumers often have to make more than one buying decision at a time. Secondly, the products only differed concerning brand name and COO and all brands were unfamiliar to the participants. Therefore, the COO could have been more important than in a real purchase environment. Thus, further research should investigate the impact of brand familiarity in a more complex retail shopping environment.

\section{References}

1. Chandon, P., Hutchinson, J.W., Badlow, E.T., Young, S. H. (2009), "Does in-store marketing work? Effects of the number and position of shelf facings on brand attention and evaluation at the point of sale", Journal of Marketing, Vol. 73, pp. 1-17. 
2. Chattalas, M., Kramer, T., Takada, H. (2008), "The impact of national stereotypes on the country of origin effect: A conceptual framework", International Marketing Review, Vol. 25 No. 1, pp. 54-74.

3. Chryssochoidis, G., Krystallis, A.,Perreas, P. (2007), "Ethnocentric beliefs and country-oforigin effects: Impact of country, product and product attributes on Greek consumers' evaluation of food products", European Journal of Marketing, Vol. 41 No. 11/12, pp. 1518-1544.

4. Helfman, J., Goldberg, J. (2011), "Eye tracking for visualization evaluation: Reading values on linear versus radial graph", Information Visualization, Vol. 10 No. 3, pp. 182195.

5. Holmqvist, K., Nyström, N., Andersson, R., Dewhurst, R., Jarodzka, H., Van de Weijer, J. (2011), "Eye tracking: a comprehensive guide to methods and measures", Oxford, UK: Oxford University Press.

6. International olive council (2016), "World olive oil figures". Available at: http://www.internationaloliveoil.org/estaticos/view/131-world-olive-oil-figures./ $(4 / 5 / 2016)$

7. Karmasin, S., Pfleger, E. (2011), "Aufmerksamkeit und Bedeutung als Schlüssel zur Werbewirkung" ("Attention and Meaning as a Key to Advertising Effectiveness"), Psychologie in Österreich, Vol. 2 No. 3, pp. 186-192.

8. Klein, C., Völckner, F. (2012), "Das klingt gut" ("Sounds good"). Available at: http://www.markenlexikon.com/texte/ma_klein_voelckner_foreignbranding 11_2012.pdf / (3/22/2015).

9. Leclerc, F., Schmitt, B., Dubé, L. (1994), "Foreign branding and its effects on product perceptions and attitudes", Journal of Marketing Research, Vol. 31, pp. 263-270.

10.Magnusson, P., Westjohn, S., Zdravkovis, S. (2011), "What? I thought Samsung was Japanese: accurate or not, perceived country of origin matters", International Marketing Review, Vol. 28 No. 5, pp. 454-472.

11.Melnyk, V., Klein, K., Völckner, F. (2013), "The double-edged sword of foreign brand names for companies from emerging countries", International Retail and Marketing Review, Vol. 9, pp. 49-72.

12.Po-Young, C., Chia-Chi, C., Chia-Yi, C., Tzu-Yun, W. (2010); "Countering negative country-of-origin effects. The role of evaluation mode". European Journal of Marketing, Vol. 44 No. 7/8, pp. 1055-1076.

13.Soto, S., Mobarec, E.,Friedmann, R. (2009), "Foreign branding: Examining the relationship between language and international brand evaluation". Innovar, Vol. 19 No. 35, pp. 9-18.

14.Tran, T., Fabrize, R. (2013), "The effect of the foreign brand on consumer perception", Journal of marketing development and competiveness, Vol. 7 No. 2, pp. 23-36.

\section{About the authors}

Ana Marija Morovican studies international business relations and has been working with the country-of-origin effect and the foreign branding strategy in different contexts for the last three years. Due to personal interest for this research field, she is writing her thesis about the topic of the paper. Author can be contacted at ana.morovican@hotmail.com.

Claudia Kummer is a Professor at the University of Applied Sciences in Burgenland, Austria. Her research interests lie in eye tracking and consumer information processing. Author can be contacted at claudia.kummer@fh-burgenland.at. 